\title{
Luz, Câmera, Giz, Sala de Aula: Ação!: Um produto educacional para o "Dessilenciamento"
}

Light, Camera, Chalk, Classroom: Action!: An educational product for "Unsilencing"

Luiza Harab da Silva Rosa ${ }^{1}$

Marco Aurélio Kistemann Jr. ${ }^{2}$

\section{Resumo}

Neste artigo apresentamos um produto educacional, resultante de uma pesquisa de mestrado profissional que envolveu o uso do cinema na sala de aula de ensino superior. Os sujeitos participantes da pesquisa eram licenciandos em Matemática e o objetivo geral foi proporcionar sessões fílmicas para convidar os participantes a argumentarem, a partir das imagens exibidas. Como resultado da pesquisa foi criado um produto educacional que apresenta sugestões de filmes, possibilitando aos professores abordar temas ligados ao cotidiano escolar e ligados ao cotidiano docente e discente. O produto ainda objetiva convidar os participantes, professores em formação permanente a "dessilenciarem-se", ou seja, a exercitar múltiplos olhares e argumentarem sobre o que assistiram nas sessões fílmicas. A relevância do produto encontra-se na possibilidade de "dar voz" aos estudantes que se tornarão professores, abrindo novas possibilidade de reflexão e criticidade acerca de temas que compõem a realidade docente, mas que ainda são pouco explorados na formação de professores. Para entendermos como as imagens são capazes de motivar um telespectador a "dessilenciar-se", nos baseamos em pesquisadores como Rosália Duarte, Adriana Fresquet, Miguel Arroyo e Marcos Napolitano.

Palavras-chave: Formação de professores. Cinema e educação. Imagens fílmicas.

"Dessilenciamento". Argumentação.

\section{Abstract}

In this article we present an educational product, resulting from a professional master's research that involved the use of cinema in the higher education classroom. The subjects participating in the research were graduates in Mathematics and the general objective was to provide film sessions to invite participants to argue from the displayed images. As a result of the research, an educational product was created that presents movie suggestions, enabling teachers to approach themes related to school everyday and linked to daily teaching and learning. The product also aims to invite the participants, teachers in permanent formation to "dissolve themselves", that is, to exercise multiple glances and to argue about what they attended in the film sessions. The relevance of the product lies in the possibility of "giving voice" to students who will become teachers, opening new possibilities for reflection and criticism on issues that

\footnotetext{
${ }^{1}$ Mestre em Educação Matemática (UFJF), Pesquisadora e Educadora no Estado do Rio de Janeiro. E-mail: harab.luiza@gmail.com

${ }^{2}$ Doutor em Educação Matemática (Unesp-Rio Claro-SP). Líder do Pesquisa de Ponta (UFJF) e Pesquisador do Departamento de Matemática (UFJF). Email: marco.kistemann@gmail.com
} 
make up the teaching reality, but which are still little explored in teacher training. To understand how the images are able to motivate a viewer to "dissolve", we rely on researchers such as Rosalia Duarte, Adriana Fresquet, Miguel Arroyo and Marcos Napolitano.

Keywords: Teacher training. Cinema and education. Film images. "Unsilencing". Argumentation.

\section{Introdução}

Muitas pesquisas de qualidade revelam formas primorosas de investigação com técnicas e instrumentos metodológicos e de análises eficientes, que geram resultados satisfatórios e, em sintonia com os objetos e a questão de pesquisa, contudo não revelam o que denominamos fundamental, os bastidores, os preparativos, os "erros" de percurso.

Brevemente, a pesquisa que gerou o produto educacional que será detalhado nesse artigo, originou-se em uma disciplina de mestrado profissional na UFJF, em que o tema da formação de professores era central, com leituras de textos e apresentação de seminários. Até esse ponto muito comum e de ocorrência natural em muitas disciplinas de graduação e pós-graduação. Entretanto, a experiência nos revelou que os textos, as dissertações e as teses por mais bem escritas que sejam, não conseguem despertar certas vozes, em particular isso ocorria em disciplinas que participamos. Muitos discentes não se sentiam encorajados ou motivados a tecer críticas a um dado autor, por creem na sua autoridade enquanto pesquisador e por ficar limitados ao que estava escrito num dado texto daquele autor.

Nossas experiências como docentes têm nos revelado ao longo da graduação e pós-graduação um silenciamento discente. Tal silenciamento se faz necessário para que aprendizagens ocorram, é claro, enquanto um sujeito explana suas ideias os outros o ouvem, refletem e criam as suas argumentações para um diálogo ou um debate. Contudo isso nem sempre ocorre, pois em muitas salas de aulas ainda reina a figura do professor detentor 
único do conhecimento com seus espectadores, os estudantes, representando tábulas rasas, nas quais o professor deve preencher com seu conteúdo programático.

Essa proposta, em nosso entendimento, além de ultrapassada, desrespeitou gerações ao anularem a possibilidade de contra argumentação e estabelecimento de ideias distintas das crenças docentes. Ao invés do desenvolvimento da criticidade, que pode ser obtida quando uma multiplicidade de cenários são cogitados, e outras multiplicidades de interpretações podem ser estabelecidas, ainda que provisoriamente, em muitos cenários escolares ainda assistimos a procedimento protocolares. Tais procedimentos e condutas arbitrárias vão calando as vozes discentes, muitas vezes com a justificativa de que conteúdos devem ser ministrados num dado período, impreterivelmente, reforçando a unicidade de um único currículo, que busca enquadrar e limitar as crenças a uma dada ideologia, qual seja a preconizada pelo livro didático ou pelo material didático escolhido e, regiamente, seguida pelo professor.

Nesses termos, a formação, por exemplo, de um licenciando que atuará futuramente como professor fica alicerçada sobre um único fundamento, o de que o professor é mais experiente, estudou mais, especializou-se e pode dizer o que deve e como deve ser feito. Ao estudante cabe ouvir, anotar, memorizar e reproduzir em instrumentos avaliativos o que foi transmitido por seu professor. Tal realidade ainda vigente em muitos ambientes escolares, de variados níveis, tem nos incentivado a buscar a voz de todos os envolvidos no processo de construção de conhecimentos, sejam eles matemáticos ou de outros âmbitos.

Dar a voz aos sujeitos que estão no processo educativo é um ato democrático e propicia o desenvolvimento da criticidade e do estado que, cremos ser imprescindível para a atuação de um professor e seus estudantes, qual seja o de estar sempre atento ao que nos rodeia, estar atento ao que se veicula em livros, em mídias, em espaços públicos. Estar atento, exercitar olhares, refletir e argumentar, ou em suma "dessilenciar-se". 
Assim, experimentamos, num dado momento, buscar 0 que denominamos de "dessilenciamento", ou buscar ouvir o que os licenciandos ou pós-graduandos falam quando assistem a uma cena cujo mote é a atuação de um professor num contexto escolar. Desse modo, além das leituras de praxe, os participantes ainda teriam cenas fílmicas com temáticas do cotidiano escolar para que o convite ao "dessilenciamento" ocorresse. Críamos que essa forma lúdica, o cinema no ambiente acadêmico fosse o disparador de criticidade e que as vozes se expressariam a partir das imagens que traduziriam uma dada realidade escolar.

Diante disso, a pesquisa "Luz, Câmera, Giz, Sala de Aula: ação!: uma investigação sobre a contribuição dos filmes na formação inicial dos professores de Matemática" (2015) foi realizada em uma universidade pública e para cada atividade escolhemos um filme que acreditávamos trazer boas reflexões sobre as concepções de um professor dentro de seu ambiente escolar. O objetivo geral da pesquisa foi convidar os licenciandos para o que denominamos, atualmente, de "dessilenciamento", externando suas concepções sobre determinado filme e tema.

Esta pesquisa tendo sido realizada num mestrado profissional teve como objetivo também, gerar um produto educacional que pudesse ser trabalhado/problematizado por professores com seus pares e por professores com seus estudantes. Nesse sentido, explicitamos as características da pesquisa em seu conteúdo, porém o objetivo do artigo é apresentar a construção do produto, sua potencialidade, detalharmos como se deu o seu uso ao longo da pesquisa e enfatizar a relevância desse produto como agente "dessilenciador" de vozes e agente potente para termos essa vozes como mais um item de valorização do conhecimento discente.

Para embasarmos teoricamente a nossa pesquisa, no tocante à formação de professores e/ou uso do cinema na educação nos utilizamos das ideias de Donald Schön, Rosália Duarte, Adriana Fresquet, Miguel Arroyo. De uma maneira geral, esses pesquisadores investigam a formação de professores e a 
educabilidade através das imagens fílmicas e alguns destacam ainda as possibilidades que esses filmes têm, se utilizados especificamente na formação inicial dos professores.

Em termos metodológicos, como forma de analisar os dados produzidos ao longo da investigação, utilizamos a Análise de Conteúdo da Laurence Bardin como forma de compreender quais os efeitos que os filmes têm sobre os professores.

\section{Algo que motivasse o "dessilenciamento": detalhando a importância e a origem de um produto educacional}

De acordo com o documento de área de ensino da Capes (2013), os mestrados profissionais (MP) da área de ensino tem peculiaridades que os distinguem dos mestrados acadêmicos (MA). Na essência, os mestrados profissionais objetivam promover conhecimentos, visando o aprimoramento da formação de professores, possibilitando investigações que geram produtos educacionais que problematizem situações formais e não-formais no contexto escolar e extraescolar.

O professor que participa de um mestrado profissional busca atualizar-se de novas metodologias de ensino e de aprendizagem, tornando-se um agente de alta relevância social, pois além de aprimorar-se, profissionalmente, produz sob orientação materiais diversos (produtos educacionais), que o auxiliarão em sua prática e que estarão disponíveis para discussão, atualização e o uso de outros professores. Ostermann (2009) explica que a diferença entre o (MP) e o Mestrado Acadêmico (MA) é que, enquanto o (MA) visa formar um pesquisador, o (MP) qualifica para o mercado de trabalho, ou seja, tem como objetivo formar profissionais que no futuro saibam utilizar a pesquisa, de modo a agregar valor a suas atividades.

É importante ressaltar que esse produto, gerado da dissertação, deve ser, nas palavras de Moreira e Nardi (p.04, 2009): "algo identificável e 
independente da dissertação". De acordo com Vailant e Souza (p.02, 2016), "os autores alegam que, apesar da dissertação ser sobre o produto, ele deve ter "identidade própria" e deve ser disponibilizado na página do programa, para que possa ser analisado e utilizado pelos professores, visando sempre à melhoria na educação básica.

Cientes das pecualiaridades do (MP), fica claro a importância de que o professor ao buscar agregar valores para sua prática se torne um autor de sua prática profissional, criando materiais pedagógicos, concretos ou virtuais, que possibilitem a construção do conhecimento de forma lúdica e gerador de criticidade. Denominamos tais materiais educativos como produtos educacionais que podem ter natureza diversa tais como: artigos, sequências didáticas, softwares, jogos, lista de problemas para serem investigados, materiais concretos para manipulação, performances, documentários, vídeos com temáticas sociais e culturais, entrevistas, depoimentos e sugestão e execução de instrumentos avaliativos diversos. Em suma, o produto educacional é, em nosso entendimento, as ideias do professor na sala de aula promovendo cenários em que os estudantes possam se constituir, a partir da mediação docente, como pesquisadores, estruturando suas formas de pensar e verbalizando seus conhecimentos, "dessilenciando-se".

De acordo com as orientações da Capes foi originário da nossa pesquisa o produto educacional denominado: "Luz, Câmera, Giz, Sala de Aula: Ação!: possibilidades fílmicas para se trabalhar com professores". Embora a investigação tenha ocorrido com sujeitos de pesquisa do curso de Matemática, licenciandos, entendemos que o produto possa ser ampliado e adequado às demandas de outras disciplinas, variando-se as escolhas dos filmes a serem problematizados, temáticas diversas, respeitando sempre a diversidade social e cultural dos envolvidos.

Em nossa investigação, buscando ouvir as vozes, o "dessilenciamento", utilizamos filmes de caráter pedagógico, ou seja, filmes que retratam de alguma forma o cotidiano da sala de aula, da escola (e seu entorno) ou do 
professor. No trabalho realizado foram selecionados quatro filmes para compor a pesquisa de campo que consistiu em trabalhar esses filmes e suas temáticas em turmas de licenciatura em Matemática.

Como produto educacional, indicamos uma coletânea de quinze filmes que poderiam igualmente ter sido escolhidos. A fim de que não se tornem puras indicações de filmes, para cada título sugerido, apresentamos os nossos comentários, visando dar possibilidades de atividades ou temas que possam gerar discussões, tendo como base o filme. Apontamos as principais discussões que podem se desenrolar sobre cada filme, discussões pertinentes que levem à reflexão de nossa prática. Estruturamos de forma que cada filme listado, apresenta uma primeira parte, em que damos a sinopse do filme, em seguida fornecemos algumas características técnicas do mesmo, para então acrescentarmos os nossos comentários e indicações para cada filme.

A seguir, exemplificamos, a partir do filme "A Onda", como a criação de uma sinopse e características do filme pode sugerir ao professor como preparar-se e preparar uma sessão, convidando os licenciandos e a comunidade acadêmica para exercitarem sua argumentação, para "dessilenciarem-se" sobre temas sociais e escolares. O fragmento a seguir é exatamente o que foi criado no produto educacional e que pode ser livremente atualizado e ampliado, a partir das demandas de cada realidade educacional ou concepção docente.

\section{"A ONDA"}

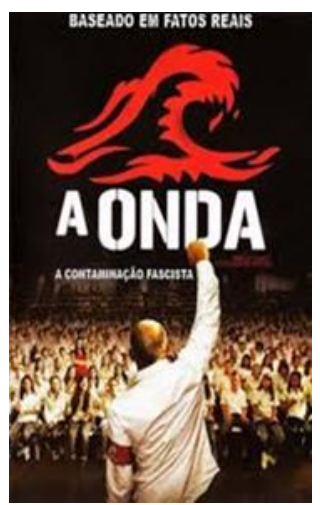


Em uma escola da Alemanha, alunos têm de escolher entre duas disciplinas eletivas, uma sobre anarquia e a outra sobre autocracia. 0 professor Rainer Wenger (Jürgen Vogel) é colocado para dar aulas sobre autocracia, mesmo sendo contra sua vontade. Após alguns minutos da primeira aula, ele decide, para exemplificar melhor aos alunos, formar um governo fascista dentro da sala de aula. Eles dão o nome de "A Onda" aomovimento, e escolhem um uniforme e até mesmo uma

saudação. Só que o professor acaba perdendo o controle da situação, e os alunos começam a propagar "A Onda" pela cidade, tornando o projeto da escola um movimento real. Quando as coisas começam a ficar sérias e fanáticas demais, Wenger tenta acabar com "A Onda", mas aí já é tarde demais.

\section{FICHA TÉCNICA}

Título Original: Die Welle / Gênero:Drama / Ano: 2008 / Nacionalidade: Alemã / Diretor: Dennis Gansel / Atores Principais: Jürgen Vogel, Frederick Lau, Jennifer Ulrich e Max Riemelt / Tempo de

\section{Duração: 108 minutos}

\section{COMENTÁRIOS}

O filme A Onda possui duas versões, uma versão americana de 1981 e outra alemã de 2008, baseadas em fatos reais de 1967 acontecidos na Califórnia, EUA. O filme da versão germânica trata do professor anarquista Rainier Wegner que durante a semana de projetos educacionais da escola em que leciona é impedido de dar aula sobre o Anarquismo e acaba tendo que dar aula de Autocracia. Em sua primeira aula, lança várias perguntas iniciais sobre o que é esse tipo de governo e num certo momento acaba chegando no exemplo do Nazismo. Diante da reação da turma que se diz já estar cansada de ouvir sobre as práticas do Führer e da crença de que é impossível tal sistema ditatorial se reestabelecer em plena Alemanha contemporânea, Reinier propõe uma experiência em sala de modo que se mantenha o regime de ditadura. Começa exigindo que seja chamado por Sr. Wegner e não mais pelo primeiro nome, cada aluno deverá também pedir permissão para falar além de ser necessária ficar de pé e darem respostas curtas. Nesse primeiro momento, o professor justifica cada uma das suas ações mostrando e apontando que uma boa postura, por exemplo, faz com que a respiração 0 ajude na concentração, assim como estar de pé ao falar ajuda na circulação 
sanguínea, que influencia em outros aspectos positivamente. Aos poucos, os alunos vão incorporando essas ideias e sem perceber estão, eles mesmos, defendendo a ideia que começou como uma proposta de trabalho final da semana dos projetos. Nos primeiros dias dessa semana, Sr. Wegner também muda os alunos de lugar de acordo com suas notas juntando os alunos com notas maiores aos alunos com notas menores assim eles podem começar a ajudar uns aos outros incitando o espírito de união, propõe também a ideia de um uniforme a fim de reforçar a união e acabar com a distinção entre eles, que em conjunto com a turma, determina que deva ser uma calça jeans e uma blusa branca. No dia seguinte, todos da turma estão de blusa branca exceto uma única estudante, Karo, que até então, participava das aulas com entusiasmo igual aos demais, mas ao vestir a blusa branca em casa, não gostou de como ficou e decidiu não a usar. Nesse dia, o professor propõe que eles tenham um nome e quer ouvir as propostas dos alunos. Karo fica com o braço levantando pedindo para dar a sua opinião e, no entanto, é ignorada pelo professor que só Ihe dá atenção quando se certifica que não há nenhuma outra ideia vinda de outro estudante uniformizado. A proposta de Karo foi ignorada e o nome escolhido é "A Onda". Daí por diante, as ideias tomam proporções desmedidas. Diante dessa situação, Karo resolve não se juntar à Onda e de fora do movimento percebe uma série de atitudes desmedidas que começam a acontecer. Fora da sala de aula, o aluno Tim que até então era ignorado pela turma e que não tinha amigos é abordado por outros dois alunos, que não são da Onda, mas que começam a implicar com ele. Dois outros integrantes da Onda que mesmo não tendo proximidade com Tim, 0 protegem firmando o ideal de serem um grupo unido e que defendem uns aos outros. Após esse episódio, numa conversa entre amigos, integrantes da Onda, surge a ideia de uma saudação para identificá-los. A partir da disciplina, união, igualdade, símbolo e saudação para caracterizá-los os próprios alunos começam a defender que as pessoas fizessem parte da Onda e repudiar aqueles que não se juntassem ao movimento. Karo e Mona, outra aluna que não entrou na ideia da Onda, são as únicas que conseguem enxergar as proporções desmedidas que $A$ Onda está ocasionando. Tentam alertar aos amigos integrantes do movimento e ao próprio professor, que diz estar tudo sob controle e que não é preciso temer. Por fim, o professor percebe que a Onda se espalhou para além da sala de aula e que os estudantes levaram muito a sério o que foi proposto quando vê pichações nas ruas e coações de pessoas, fazendo-o perceber que os acontecimentos fugiram do seu controle. Numa reunião extraordinária com todos os integrantes da Onda, o professor faz os alunos enxergarem que as proporções tomadas são incabíveis e retoma à primeira aula, quando eles mesmos disseram ser impossível se reestabelecer um sistema ditatorial no momento contemporâneo e, no entanto, é exatamente isso que está acontecendo, os alunos estavam fazendo aquilo que Ihes era mandado pela construção da Onda. Ao se darem conta disso tudo os alunos ficam em choque, principalmente 0 aluno Tim, que antes do movimento era sozinho e diz ter se encontrado dentro da Onda. 
Com o término do filme, após ficar claro qual a intenção da exibição, qual seja a de promover um debate, a partir das imagens fílmicas, com a ocorrência de argumentações e, por conseguinte, o "dessilenciamento" discente e dos demais participantes, os autores da pesquisa teceram algumas considerações no produto, referentes a esse filme, e que podem ser (re)pensados pelos docentes e ampliados a partir de sua experiência e contextos sociais e culturais em que se encontram inseridos. $O$ seguinte fragmento exemplifica o que enfatizamos:

Com o desfecho da estória muitas ponderações podem ser feitas. O que começou como uma proposta de trabalho tomou dimensões inimagináveis para fora da sala de aula. Enquanto professores, temos que tomar muito cuidado com o que dizemos e como tratamos uns aos outros. Professor não deixa de ser sempre um líder dentro de sala de aula, ou no mínimo, um exemplo de alguém com mais experiência de vida. 0 propósito da Onda traz consigo duas consequências: uma boa e uma ruim. Olhando por um lado, alunos como Tim, ganharam uma identidade por fazer parte de um único grupo. Grupo esse que se ajuda, que vê em todos os seus integrantes uma igualdade e merecimento dos mesmos direitos. O lado ruim foi o extremismo de acreditar que quem não fizesse parte do grupo não merecia respeito, de se colocarem num patamar acima dos demais não integrantes do grupo. Enquanto professor, devemos instigar que nossos alunos queiram o bem uns dos outros, mas mais que isso, que se vejam como um grupo e que cada perda (reprovação) é o grupo todo que está perdendo um integrante, mas é de extrema importância mostrar que qualquer outra pessoa fora desse grupo é igualmente merecedora de respeito e compaixão. Essa noção de construção de identidade de turma é muito bem-vinda! Outro fator que o filme aborda e que você professor e os demais professores devem estar atentos também, é quanto a vida que nossos alunos levam fora da escola. Muitas vezes, o professor não tem noção das atitudes dos alunos fora daquele ambiente e acabam mantendo uma didática tão alheia da realidade do aluno que o professor se perde no seu mundo. No caso do filme, o professor não imaginava as proporções além dos muros da escola e que acabaram deixando ele com a falsa impressão de que estava no controle da situação. Outro cuidado especial é quanto à forma como nós mesmos nos retratamos a alguns alunos. Talvez os alunos não tivessem começado com a ideia de que quem não faz parte da Onda é inferior se o professor, naquele primeiro dia em que Karo foi sem o uniforme estipulado, não a tivesse ignorado. Essa atitude foi de certa forma uma maneira de mostrar que ela não tinha 
voz igual aos outros, que era diferente.

\section{Relevância do Produto e Fundamentações Teóricas}

Um produto educacional é produzido para ser utilizado em sala de aula, servindo de complemento aos materiais pedagógicos que o professor recebe, além do livro didático. Como é um material autoral, em geral, confeccionado com a participação ou mediação de um orientador, espera-se que seja problematizado e atualizado, a partir das experiências com os estudantes a que se dirige aquelas propostas didáticas presentes no produto.

Esse é o primeiro desafio de um produto educacional, qual seja de não ficar estacionado em prateleiras de bibliotecas ou armários como, em geral ficam as teses e dissertações oriundas de pesquisas relevantes, mas inacessíveis aos professores que necessitam cumprir longas jornadas em duas ou mais escolas. Nesse contexto, a criação e compartilhamento de um produto educacional torna esse material dinâmico e capaz de subsidiar as práticas pedagógicas de professores que não participaram diretamente de sua idealização e concretização.

No caso do produto gerado, a partir da pesquisa citada nesse artigo, uma primeira preocupação dos autores era adequar seu formato e proposta exequível e de fácil utilização em ambientes escolares ou não escolares. A proposta da pesquisa, detalhada na dissertação, e que originou no produto era, a partir de imagens fílmicas, problematizar temas referentes ao cotidiano do professor, à rotina escolar e aos desafios enfrentados pelos professores em seus momentos iniciais no magistério. Em geral, os estágios supervisionados ou as disciplinas na graduação, nos diversos departamentos, não tem dado conta da diversidade de temas que devem ser abordados, e que hoje são relevantes tais como a diversidade, questões de gênero, bullying, cultura e redes sociais, tolerância, etc. 
Assim, os filmes escolhidos para a pesquisa de campos e, posteriormente, que foram sugeridos no produto educacional trazem temas que reforçam a responsabilidade do professor com relação a sua prática, com o que fala para seus estudantes, suas crenças e, sobretudo, o exemplo de autoridade e poder que esse profissional constitui para seus estudantes e para a comunidade escolar.

Salientamos que o uso de filmes como recurso didático para introduzir a matéria já é uma prática muito mais comum nas áreas de História, Geografia, Filosofia e no primeiro segmento do Ensino Fundamental, com o uso de documentários e curta-metragens para a problematização de temas.

Tivemos várias possibilidades de filmes para trabalhar com os nossos sujeitos de pesquisa e, nesse sentido, destacamos a fala de Arroyo (2003) que nos diz que "A poesia, o cinema, o romance são algumas das artes que têm se sensibilizado com a poética e estética do magistério." (ARROYO, 2003, p. 118). A poética do magistério pode ser representada de diferentes formas artísticas, mas o cinema talvez seja onde ela é mais representada.

A quantidade de filmes que retratam o cotidiano da escola, do professor e dos estudantes é enorme e, sabendo disso, nossa ideia foi selecionar apenas alguns para usarmos em nossa pesquisa. Por mais que o desejo de trabalhar com muitos fosse grande, tínhamos um limitador de tempo e acreditávamos em uma prática que geraria e gerou continuidade, ou seja, os próprios estudantes poderão ter autonomia de escolher outros filmes para "dessilenciarem" fora dos momentos de nossas atividades. E a continuidade veio com um projeto que detalharemos a seguir.

Quando lemos os Parâmetros Curriculares Nacionais (Matemática), também encontramos indícios de que o uso desses recursos midiáticos é bemvindo, porém sempre direcionando para a análise e reflexão dentro da disciplina na qual eles estão inseridos, no nosso caso, a aula de Matemática. Assim,

Recursos didáticos como jogos, livros, vídeos, calculadoras, computadores e outros materiais têm um 
papel importante no processo de ensino e aprendizagem. Contudo, eles precisam estar integrados a situações que levem ao exercício da análise e da reflexão, em última instância, a base da atividade matemática (BRASIL, 1997, p. 19)

Fazer uma atividade isolada como forma de ocupar uma turma é uma chance desperdiçada de se ter aprendizados, mesmo que aquele filme não tenha nenhuma relação com um conteúdo específico da disciplina em questão,

[...] pois o cinema é o campo no qual a estética, o lazer, a ideologia e os valores sociais mais amplos são sintetizados numa mesma obra de arte. Assim, dos mais comerciais e descomprometidos aos mais sofisticados e "difíceis", os filmes têm sempre alguma possibilidade para o trabalho escolar. 0 importante é o professor que queira trabalhar sistematicamente com o cinema se perguntar: Qual o uso possível deste filme? A que faixa etária a escolar ele é mais adequado? Como vou abordar o filme dentro da minha disciplina ou num trabalho interdisciplinar? Qual a cultura cinematográfica dos meus alunos? (NAPOLITANO, 2004, p. 11-12)

Essas quatro perguntas apresentadas nos guiaram para a preparação do produto educacional com a sugestão dos filmes e sua relevância.

A pesquisadora da UFRJ, Adriana Fresquet, que foi um dos nossos referenciais teóricos da dissertação, conduz um projeto intitulado CINEAD realizado no Colégio de Aplicação da Universidade Federal do Rio de Janeiro (CAp - UFRJ). Fresquet relata uma de suas atividades em que foi realizada uma oficina com os alunos no contraturno das aulas, de forma que eles aprendessem com o cinema desde a sua preparação por trás dos bastidores, até a exibição dos filmes produzidos por eles mesmos.

Fresquet ainda aponta as possibilidades que o cinema pode trazer, ao ser inserido na vida da criança ao acreditar "no cinema e na sua possibilidade de intensificar as invenções de mundo, ou seja, da possibilidade que o cinema tem de tornar comum o que não nos pertence, o que está distante, as formas 
de vida e as formas de ocupar os espaços e habitar o tempo". (FRESQUET, 2013, p. 25).

Se nas ciências humanas e na educação básica, o uso de filmes têm buscado problematizar temas referentes aos conteúdos curriculares, na área de ciências exatas, nossas pesquisas bibliográficas que compuseram nossa revisão de literatura apontou uma severa escassez de propostas. Como exceções a essa escassez, destacamos também as ações da educadora matemática Romélia Mara Alves Souto que por meio da História da Matemática e do Cinema problematizou temas referentes a essa disciplina das Ciências Exatas e imagens fílmicas com temáticas históricas e científicas.

As ações de Souto (2013) buscavam discutir relações didáticas possíveis entre o Cinema e a História da Matemática, crendo que tais relações podem contribuir para a formação de professores de Matemática, constituindo um ambiente favorável à aprendizagem matemática e ao desenvolvimento da criatividade e da argumentação, a partir do que é problematizado nos filmes exibidos.

Ainda, nas pesquisas realizadas por Coelho e Viana (2013), Viana (2009; 2010; 2011) e Viana, Rosa e Orey (2011) constatamos a preocupação desses educadores matemáticos que vão ao encontro de nossas preocupações. Nessas pesquisas, podemos resumir as questões à questão: "De que modo os filmes, como meios de ensino e aprendizagem, têm sido utilizados em cursos superiores?". Os pesquisadores citados concluem em suas investigações que que, em geral, a grande maioria dos educadores matemáticos não utilizam filmes em sala de aula como recurso didático, embora considerem importante seu uso como meio de ensino.

Coelho e Viana (2013) enfatizam a relevância da utilização do cinema como ferramenta educativa, de modo que ao professor cabe descobrir nos filmes, o processo de escolarização e retirar deles reflexões que instiguem o aluno a raciocinar mais profundamente, constituindo-se tal ação como a chave 
da utilização do cinema na sala de aula. Para as educadoras, a questão é desvendar, pois, como as aulas de Matemática podem ser favorecidas por este recurso.

Complementamos tal afirmativa, concordando com Viana (2009) quando esta educadora matemática enfatiza que há necessidade de procurar meios pedagógicos para provocar a aprendizagem dos alunos, uma vez que um dos objetivos da educação é encontrar instrumentos apropriados para implementação das novas tecnologias de informação e comunicação no processo de ensino-aprendizagem.

Recordamos que o filme "Pato Donald no País da Matemágica" também é utilizado como um recurso didático para introduzir alguns dos conteúdos de Matemática que o desenho aborda. Alguns professores utilizam o mesmo como forma de divulgação de uma Matemática lúdica e presente no dia a dia, já que atualmente a Matemática é tida por muitos estudantes como disciplina desinteressante e inútil.

Inferimos que um filme como esse, tem um papel interessante dentro da sala de aula, por não ser de difícil compreensão e por trazer consigo a ludicidade da Matemática e a noção de que há Matemática em muitas coisas ao nosso redor. Muitas vezes, os estudantes herdam dos responsáveis a visão da Matemática como vilã e disciplina cheia de regras e nós professores de Matemática, temos o desafio de desmistificar esse preconceito. A utilização de cenas fílmicas é uma metodologia alternativa em nosso entendimento que deve ser experimentada e nosso produto educacional se propõe a isso.

\section{Potencial do Produto: um fruto gerado da pesquisa realizada}

Os institutos de ciências exatas brasileiros, para ficarmos restritos a contextos nacionais, têm uma peculiaridade, os estudantes passam boa parte de seu tempo estudando para provas de Matemática, Física, Estatística, etc e após alguns períodos passam a cursar disciplinas denominadas de pedagógicas nas faculdades de educação. 
Nas faculdades de educação devido às especificidades das disciplinas há espaços para que os estudantes argumentem sobre o que leem, há discussões e seminários em que as vozes desses estudantes podem reverberar suas crenças. Contudo, de acordo com nossa experiência e a pesquisa que deu origem ao produto educacional, há limitações e muitos estudantes acabam por emitir por sua voz o conteúdo e teor das vozes dos autores que lê.

Se voltarmos para a realidade dos institutos de ciências exatas, o gradual silenciamento das vozes ocorre à medida em que os períodos oferecem disciplinas com maior grau de dificuldade e abstração. Nesses períodos em licenciaturas e bacharelados, com poucos estudantes, quase só a voz docente é ouvida. Isso contraria a ideia de dois professores com os quais convivemos, Roberto Baldino e Romulo Lins, ambos da Unesp-SP que em suas aulas defendiam que a Matemática se aprende falando e ensina-se ouvindo também. Entendemos assim, que conhecimentos se consolidam a partir das enunciações que emitimos, e que nossos interlocutores nos auxiliam na construção de significados a partir do momento em que compartilhamos de um mesmo campo semântico.

Nesse sentido, a transmissão de conhecimentos, numa aula, parece-nos inconcebível, pois isso reificaria um bom ensino e em consequência desse bom ensino uma aprendizagem significativa. Ao emitirmos nossas enunciações em sala e, em seguida, pedirmos aos estudantes que expliquem o que entenderam de nossas falas, percebemos em que campo semântico eles se situam e, em grande parte não coincide com o nosso.

Ou seja, o dessilenciar-se por parte do discente auxilia o professor a regular a aprendizagem, a entender os mecanismos que regem a aprendizagem de cada discente. A voz situa o conhecimento do estudante e caberá ao docente ouví-la e guiar o seu ensino em direção a uma aprendizagem significativa. Porque "falta-nos deixarmos contaminar por outras formas de ver, sentir e ler a realidade. A escola e a docência são reféns de uma linguagem e de uma leitura única." (ARROYO, 2003, p. 119). 
A proposta da nossa pesquisa consistiu em compreender de que forma 0 uso de imagens fílmicas, sejam vídeos ou filmes, poderiam contribuir para a formação inicial do professor de matemática, oportunizando espaços de diálogo, argumentações a partir das imagens e debates que respeitassem a diversidade de opiniões e crenças sobre os temas exibidos. A potencialidade do nosso produto educacional, que busca o "dessilenciamento" discente por meio de exibição de imagens fílmicas, revela-se nesse ínterim, qual seja o de provocar nos estudantes a vontade de (contra)argumentar a partir de cenas que possam revelar suas crenças, seus conhecimentos, orientando futuras ações e decisões em sala de aula.

A pesquisa realizada culminou, por meio de seus resultados parciais, influenciando a criação de um projeto intitulado Cinemática-Cinema e Debate nas Ciências Exatas. O objetivo desse projeto, inspirado na pesquisa realizada por Luiza Harab, coaduna-se com os objetivos da pesquisa realizada, na medida em que diretrizes para as licenciaturas do Ministério da Educação suscitaram a problematização e inclusão nas disciplinas de temas como Diversidade, Relações de Gênero e tópicos relacionados à Diversidade Étnico-Racial no ambiente universitário.

Diante dessa nova demanda de temas nas licenciaturas, questionamonos: "Como problematizar, nos contextos das disciplinas de Matemática, discussões envolvendo esses temas e temas que tangenciam estes como Alteridade, Ética e Inclusão?".

A pesquisa realizada com imagens fílmicas com a participação de licenciandos pode ser uma das respostas a esse questionamento. Sua realização oportunizou o surgimento do Cinemática, com os objetivos análogos ao da pesquisa a que se refere esse artigo, qual seja promover discussões e reflexões sobre temas da profissão docente com professores em formação inicial, através de filmes, cujos roteiros giravam em torno de um ambiente escolar e as suas idiossincrasias.

Uma diferença que deve ser apontada é que nas sessões promovidas no 
Cinemática, o "dessilenciamento" envolvia e envolve licenciandos em fase inicial e final do curso, graduandos de diversos cursos e professores da educação básica e superior.

\section{Considerações Finais}

Nosso produto educacional consistiu de um catálogo com diversos títulos, filmes e documentários, com os destaques educacionais possíveis para cada um, bem como a ficha técnica de cada uma dessas mídias. Vislumbramos algumas situações em que esse material poderá ser útil, provocativo e um convite ao "dessilenciamento", como ocorreu no estudo piloto e no estudo posterior.

Para os profissionais que trabalham com a formação de professores, inicial ou continuada, e desejam acrescentar à sua prática formativa atividades com os filmes de caráter pedagógico, o nosso produto final poderá servir como fonte de consulta para esses filmes, bem como alguns levantamentos relevantes do que cada filme pode conduzir em termos de discussão e reflexão. O produto educacional também pode servir como guia para grupos de estudo que desejam, por meio dos filmes, levantar discussões guiadas pelo enredo apresentado em cada um deles. Essas são duas possíveis finalidades para o produto apresentado, mas após sua consulta, esperamos que novas propostas de atividades sejam geradas a partir dele.

Nosso objetivo foi, por meio dos filmes, promover o "dessilenciamento" acerca das problematizações das situações escolares e não escolares, convidando os licenciandos a se posicionarem criticamente sobre o que foi exibido. Além de possibilitar momentos para exercitar o olhar, por meio das imagens fílmicas apresentadas.

Recordamos Duarte (2002) que nos diz ser esse processo, parte do desenvolvimento da competência para ver e que, entendemos ser uma competência que todos os professores deveriam primar em desenvolver. Ver para além do enxergar meramente, analisando e debatendo sobre cenas que podem extrapolar as diversas concepções de ensino que os estudantes e 
professores têm em sua realidade, revelando que essas que eles conhecem e, às vezes, se acostumam não são as únicas.

Para Fresquet (2013, p.9),"as artes provocam, atravessam, desestabilizam as certezas da educação, perfuram sua opacidade e instauram mistério no seu modo explícito de se apresentar, ao menos, no espaço escolar".

Esse foi o tempo todo nosso objetivo com o produto educacional elaborado que, posteriormente colocamos em ação com o Cinemática-Cinema e Debate nas Ciências Exatas. Inspirados em Fresquet (2013), devemos provocar o desejo de "dessilenciar-se", desestabilizar as crenças cristalizadas pelos participantes, convidar à educação crítica do olhar, da reflexão e do repensar práticas educacionais nas ciências exatas. Destacamos que o projeto Cinemática vê ocorrendo em eventos da graduação e nas salas de aula dos autores com licenciandos e mestrandos.

\section{Referências}

ARROYO, M. Uma Celebração da Colheita. In: TEIXEIRA, I., LOPES, J. (Orgs.). A Escola vai ao Cinema. Belo Horizonte: Autêntica Editora, 2003. p.117 - 126.

BARDIN, L. Análise de Conteúdo. Lisboa, Portugal; Edições 70, LDA, 2009.

BRASIL. Secretaria de Educação Fundamental. Parâmetros curriculares nacionais: matemática / Secretaria de Educação Fundamental. - Brasília: MEC/SEF, 1997.

CARRIÈRE. J. A linguagem secreta do cinema. Rio de Janeiro: Editora Nova Fronteira, 2014. COELHO, Roseane Moreira de Figueiredo; VIANA, Marger da Conceição Ventura. A utilização de filmes em sala de aula um breve estudo no Instituto de Ciências Exatas e Biológicas da UFOP. Revista da Educação Matemática da UFOP. v.1, p.89 - 97, 2011.

COELHO, R.; VIANA, M. C. V. A utilização de filmes em sala de aula um breve estudo no Instituto de Ciências Exatas e Biológicas da UFOP. Revista da Educação Matemática da UFOP, s. I., v.1, p.89 - 97, 2013.

DUARTE, R. Cinema \& educação. Belo Horizonte: Autêntica, 2002.

FIORENTINI, D.; NACARATO, A. M. Cultura, Formação e Desenvolvimento Profissional de Professores que ensinam Matemática: investigando e teorizando sobre a prática. São Paulo: Musa, 2005. 
FRESQUET, A. Cinema e educação: Reflexões e experiências com professores e estudantes de educação básica, dentro e fora da escola. Belo Horizonte: Autêntica, 2013.

MOREIRA, M. A.; NARDI, R. O mestrado profissional na área de ensino de Ciências e Matemática: Alguns esclarecimentos. Revista Brasileira de Ensino de Ciência e Tecnologia, Ponta Grossa, v. 2, n. 3, p. 1-9, 2009.

NAPOLITANO, M. Como usar o cinema na sala de aula. 2a․ ed. São Paulo: Contexto, 2004.

OSTERMANN, F.; REZENDE, F.. Projetos de desenvolvimento e de pesquisa na área de ensino de Ciências e Matemática: uma reflexão sobre os mestrados profissionais. Caderno Brasileiro de Ensino de Física, Florianópolis, v. 26, n. 1, p.66-80, abr. 2009.

ROSA, L.H.S. Luz, Câmera, Giz, Sala de Aula: Ação!: uma investigação sobre a contribuição dos filmes na formação inicial dos professores de Matemática. Dissertação de Mestrado Profissional em Educação Matemática. Universidade Federal de Juiz de Fora, Juiz de Fora, 2015.

SCHÖN, D. Educando o Profissional Reflexivo: um novo design para o ensino e a aprendizagem. Porto Alegre: Artmed, 2000.

TEIXEIRA, I. LOPES, J. A Escola vai ao Cinema. Belo Horizonte: Autêntica, 2003.

TARDIF, M. Saberes docentes e formação profissional. Petrópolis: Vozes, 2002.

VAILANT, C.C.R; SOUZA, M.J.F.S. Características dos produtos educacionais desenvolvidos nos mestrados profissionais da Região Centro-Oeste do Brasil. In IV Seminário de Pós-Graduação em Educação para Ciências e Matemática. IFGO-Jataí, 2016.

VIANA, M. C. V. A formação de professores vai ao cinema: 51 roteiros de filmes para serem usados na sala de aula. Ouro Preto: UFOP, 2011. 209 p. 